\title{
Entre Haïti et le Québec. La conceptualisation de l'oraliture et de l'homme américain dans la position exotopique de Maximilien Laroche
}

\section{Sara Del Rossi}

Numéro 116, été 2020

Dossier spécial Léon-Gontran Damas

URI : https://id.erudit.org/iderudit/1071055ar

DOI : https://doi.org/10.7202/1071055ar

Aller au sommaire du numéro

Éditeur(s)

Department of French, Dalhousie University

ISSN

0711-8813 (imprimé)

2562-8704 (numérique)

Découvrir la revue

Citer cet article

Del Rossi, S. (2020). Entre Haïti et le Québec. La conceptualisation de l'oraliture et de l'homme américain dans la position exotopique de Maximilien Laroche. Dalhousie French Studies, (116), 127-137. https://doi.org/10.7202/1071055ar
Résumé de l'article

À partir des années 1960, la critique littéraire québécoise connaît un élan innovateur surtout dans le cadre de la littérature comparée. Maximilien Laroche (1937-2017), critique et professeur haïtien installé au Québec depuis les années 1960, s'insère dans cette vague en établissant des ponts et points de convergence entre les littératures québécoise et haïtienne. Cet article se propose d'analyser la pensée de Laroche, en prenant pour objet sa situation de l'entre-deux, marquée par l'interface Haïti-Québec qui engendre ses deux concepts clef : «l'homme américain » et « l'oraliture ». À travers l'analyse de ses principaux ouvrages, nous essayerons de montrer que la position exotopique (Bakhtine) de Laroche, entre les aires culturelles et littéraires du Québec et d'Haïti, contribue à une ouverture inédite aux études comparées interaméricaines, à la fois continentales (le Québec, les États-Unis, Le Brésil et la Chine) et insulaires (l'apport des croyances amérindiennes et de la culture populaire haïtienne). Toutefois, cette mondialisation du regard chez Laroche n'est jamais déconnectée de sa culture d'origine, au contraire, elle lui permet de remettre en valeur l'oraliture haïtienne, focalisée sur les croyances et valeurs ancestrales. 


\title{
Entre Haïti et le Québec. La conceptualisation de l'oraliture et de l'homme américain dans la position exotopique de Maximilien Laroche. ${ }^{1}$
}

\author{
Sara Del Rossi
}

\section{Les Haïtiens au Québec}

1 es rapports entre Haïti et le Québec sont toujours d'actualité, comme le montre l'ouvrage récent de Sean Mills, Une place au soleil : Haïti, Haïtiens et la refondation $d u$ Québec, publié en 2016, où l'auteur examine « de quelle manière Haïti, les migrantes et migrants haïtiens ont influencé et marqué le développement d'une société occidentale [québécoise] » (quatrième de couverture). Historiquement, le début des rapports entre ces deux anciennes colonies françaises remonte à la première moitié du $\mathrm{XX}^{\text {ème }}$ siècle, cependant les années 1960 marquent un tournant décisif. À cette époque en Haïti l'on assiste à la déflagration de la violence dictatoriale de François Duvalier et en même temps, au Québec, la société québécoise prend conscience de son identité collective : celle d'un Québec laïque, moderne et social-démocrate. Dans un jeu de déséquilibres, à la répression totalitaire fait écho une ouverture sociale et politique, qui comporte aussi l'ouverture des frontières québécoises aux rescapés, comme l'affirme Lyonel Icart :

À la faveur de deux événements concomitants, le décollage économique du Québec, dans la foulée de la Révolution tranquille, qui entraîna un appel de compétences, et la féroce dictature de Duvalier père qui s'abattait sur Haïti à partir de 1957, poussant à l'exil des milliers de professionnels, Haïti deviendra le premier pays fournisseur d'immigrants du Québec. (49)

C'est avec la première grande vague migratoire des années 1960 qu'une véritable diaspora haïtienne débute. La plupart des réfugiés du régime dictatorial font partie de l'élite haïtienne, il s'agit de nombreux professionnels et intellectuels ; ce sont les " migrants éduqués » (Mills 105), auxquels s'opposeront les «migrants pauvres » (Mills 105) des vagues migratoires successives, en particulier à partir des années 1970. Si dans d'autres pays d'accueil, comme les États-Unis, les cerveaux haïtiens sont utilisés en tant que simple main-d'œuvre, au Québec ils font partie des secteurs tertiaire et quaternaire :

À Montréal, la situation est tout à fait différente. Plutôt que le déclassement que l'élite haïtienne subit aux États-Unis, les exilés au Québec voient leurs compétences reconnues et, comme ils s'expriment en français à une époque où le Québec a besoin de professionnels compétents de langue française, ces hommes et ces femmes trouvent des emplois de professeurs et d'enseignants, d'infirmières, de médecins et d'ingénieurs. Tout en vidant Haïti d'une bonne partie de sa main-d'œuvre qualifiée, l'exode des années 1960 apporte un savoirfaire technique indéniable au Québec, où les services publics sont en pleine expansion. (Mills 121)

La langue française n'est pas seulement une compétence avantageuse pour l'obtention d'un poste, un atout à adjoindre au CV, mais un outil d'affirmation identitaire et de combat commun. L'expression en langue française rapproche les intellectuels haïtiens des intellectuels québécois. En effet, parmi les «milliers de professionnels » haïtiens on

1. Le présent article a été réalisé grâce à la subvention du projet Dynamika rozwoju haitańskiej opowieści ludowej (n ${ }^{\circ}$ 2017/27/N/HS2/00675) accordée par Narodowe Centrum Nauki, Polska (Centre National de Recherche Scientifique, Pologne). 
retrouve les membres du mouvement culturel Haïti Littéraire ${ }^{2}$ qui, pendant les premières années de la dictature duvaliériste, avait cherché à résister à la répression en animant la vie culturelle du pays. Contraints à l'exil, après avoir "visité» les cellules des prisons haïtiennes, les membres de ce mouvement ont continué à lutter pour la culture de leur pays dans les rues de Montréal, en créant des espaces de diffusion culturelle, comme par exemple la lecture publique de leurs ouvrages au restaurant-boîte Le Perchoir d'Haïti. C'est au cours de ces soirées, appelées Lundis littéraires, que l'intelligentsia haïtienne rencontre les intellectuels et les écrivains québécois, en tissant des liens de plus en plus étroits, comme en témoigne Anthony Phelps :

Ce premier groupe d'écrivains haïtiens exilés va créer les Lundis du Perchoir d'Haïti de Montréal. Ils jouent le rôle de passeurs, amorcent les premiers rapports entre les écrivains canadiens français [sic] - qui allaient bientôt se nommer québécois [sic] - et leurs confrères d'Haïti. Les poètes Gaston Miron, François Piazza, Nicole Brossard, Denise Boucher, Juan Garcia, Claude Péloquin, Gilbert Langevin, Raoul Duguay, Paul Chamberland, Michel Beaulieu, Yves Leclerc, Pierre Bertrand sont invités à se joindre à nous, pour des lectures de poèmes. Miron donne à ce groupe informel le nom de Batèche-batouque. En Haïti, nous avions l'habitude de faire des lectures publiques de nos poèmes, mais je crois que pour les Québécois ce fut une expérience nouvelle. Mon poème : Présence, était fort populaire parmi les Haïtiens qui faisaient la cour aux québécoises [sic], en leur murmurant des extraits du poème : «Voici que je te tiens entre mes bras comme une amphore... ». ("Québec-Haïti »s.p.)

Les relations entre les intellectuels haïtiens et les «nègres blancs d'Amérique $»^{3}$ ne sont pas seulement constatées par les témoignages des protagonistes et leurs récits, mais aussi par de nombreuses études académiques qui explorent les liaisons entre les deux pays, comme les travaux de Max Dorsinville ${ }^{4}$ et Jean Jonaissant ${ }^{5}$, sans oublier l'apport fondamental du pionnier Auguste Viatte ${ }^{6}$. Cet article s'inscrit dans la même lignée, mais au lieu de se focaliser sur les échanges entre plusieurs protagonistes de la scène haïtiennequébécoise, il se penche sur le chercheur universitaire haïtien-québécois Maximilien Laroche et, plus particulièrement, sur sa démarche critique en littérature comparée. L'objectif est d'examiner comment la position doublement exotopique de Laroche, tant par rapport à la littérature haïtienne que par rapport à la littérature québécoise, a profondément influencé les concepts clés de sa pensée : «l'oraliture » et « l'homme américain ».

\section{L'exotopie larochienne}

Né en 1937 au Cap Haïtien, Maximilien Laroche s'intéresse, déjà à partir de l'école secondaire, à la littérature haïtienne, spécialement à celle qui se situe en dehors des canons littéraires classiques, comme il en témoigne dans un entretien :

Tout a commencé à l'école secondaire. Nous avions dans notre collège un cercle d'études dont la règle était que chacun devait, de façon régulière, présenter des exposés sur des sujets de son choix. J'ai voulu profiter de ce cadre pour étudier

2. Voir Phelps « Haïti Littéraire : Rupture et nouvel espace poétique. Exemplaire fraternité ».

3. Nous nous référons à l'ouvrage Nègres blancs d'Amérique (1968) de Pierre Vallière, considéré comme le manifeste du mouvement de libération nationale québécois.

4. Voir Caliban without Prospero: Essay on Quebec and Black Literature (1974) et Le Pays natal: Essais sur les littératures du Tiers-Monde et du Québec (1983).

5. Voir «Des récits haïtiens au Québec (1937-1995). Repères pour une histoire » (1997) et « De l'apport migratoire à la littérature québécoise » (1993).

6. Voir Histoire littéraire de l'Amérique française (1954). 
les auteurs haïtiens qui alors n'étaient pas au programme des écoles ni au baccalauréat. (Laroche interviewé par Jobnel s.p.)

Ensuite, grâce à une bourse accordée par le Conseil des Arts du Canada, il obtient sa licence à l'Université de Montréal, où il arrive en 1960. La situation dictatoriale en Haïti le contraint à rester au Québec pour poursuivre ses études et se spécialiser en littérature comparée. Il se consacre principalement à la mise en parallèle des littératures francophones, en particulier haïtienne et québécoise. La création à l'Université Laval du Groupe de recherche sur les littératures de la Caraïbe (GRELCA) lui permet de continuer ses recherches et de publier plusieurs ouvrages à ce sujet. Ces travaux s'insèrent dans la vague des études comparatistes au Canada qui, vers la fin des années 1960, connaissent un élan important et pionnier. Laroche, jusqu'à sa mort survenue en 2017, a contribué non seulement à l'établissement de ponts et points de convergence entre le Québec et Haïti, mais aussi à une ouverture inédite au comparatisme interaméricain et mondial, qui inspirera les travaux de nombreux spécialistes comme Max Dorsinville et Jean Jonaissant, mais aussi Berrouët Oriol $^{7}$, Jozef Kwaterko ${ }^{8}$ et, dans des temps plus récents, Kanaté Dahouda ${ }^{9}$ et Ching Selao ${ }^{10}$. Son regard innovateur a ses origines dans sa double appartenance, haïtienne et québécoise, c'est-à-dire dans sa position exotopique.

L'exotopie est un concept bakhtinien qui remonte aux premiers écrits (1920-1930) du théoricien russe, qui utilise ce terme pour expliquer le rapport entre l'auteur et ses personnages. Dans cette première phase de sa pensée, Mikhaïl Bakhtine considère la position exotopique comme la situation par laquelle l'auteur, extérieur aux personnages et aux événements qui le concernent, peut construire ceux-ci et les faire évoluer en toute liberté, car il est capable d'avoir la perception entière de l'univers fictif dont il est le créateur. Cela implique aussi la représentation, mais surtout la perception de la manière dont « les choses du monde extérieur (un espace) seront représentées par rapport au héros » (Bakhtine cité par Peytard 59). Seulement, en 1970 la notion est employée par Bakhtine pour décrire les rapports entre les cultures :

Dans le domaine de la culture, l'exotopie est le moteur le plus puissant de la compréhension. Une culture étrangère ne se révèle dans sa complétude et dans sa profondeur qu'au regard d'une autre culture (et elle ne se livre pas dans sa plénitude car d'autres cultures viendront qui verront et comprendront davantage encore). (Bakhtine 348).

Selon Bakhtine, c'est seulement en explorant une culture autre que nous pouvons pleinement comprendre notre propre culture, car les outils utilisés pour l'analyse permettent l'éclosion de nouveaux sens. Cependant, la « rencontre dialogique des cultures en présence » (Bakhtine 348) ne comporte aucune fusion, au sens d'amalgame; elle favorise plutôt un enrichissement mutuel, qui conserve la spécificité de chaque culture. C'est ce que Todorov appelle « compréhension créatrice » dans sa critique des écrits de Bakhtine :

Bien sûr, entrer sans une certaine mesure dans une culture étrangère, regarder le monde à travers ses yeux, est un moment nécessaire dans le processus de sa compréhension ; mais si celle-ci s'épuisait par ce seul moment, elle eût été un

7. Voir «L’émergence des écritures migrantes et métisses au Québec » (1992).

8. Voir « Les fictions identitaires des romanciers haïtiens du Québec » (2002).

9. Voir « Aimé Césaire, Paul Chamberland et le pays de l'exil » (2001) et « Littératures francophones des Antilles et du Québec : Pôles et parallélismes » (2002).

10. Voir « Les mots/ maux de l'exil/ex-île. Les romans de Marie-Célie Agnant », « Les fills d’Aimé Césaire. De la Martinique au Québec » et «Échos de la négritude césairienne chez Gaston Miron et Paul Chamberland ». 
simple dédoublement et n'eût apporté rien de neuf ni d'enrichissant. La compréhension créatrice ne renonce pas à soi, à sa place dans le temps, à sa culture, et n'oublie rien. (Mikhaïl Bakhtine 169)

C'est justement cette situation de l'entre-deux, ce dépaysement positif sans que l'identité ne soit oubliée, qui a permis à Laroche de développer ses recherches en deux mouvements alternés et complémentaires: d'un côté une vision d'ensemble des Amériques, pour une comparaison interaméricaine des littératures du Sud au Nord du continent; de l'autre côté, une focalisation directe non seulement sur la littérature haïtienne, mais également sur une partie de celle-ci : l'oraliture.

Le premier ouvrage de Laroche, Le miracle et la métamorphose. Essai sur les littératures du Québec et d'Haïti (1970), ébauche ce double mouvement caractéristique de toute son œuvre. Il s'agit d'une mise en parallèle entre différents genres de la littérature haïtienne et québécoise, tels que le roman, la poésie et le théâtre. L'étude s'ouvre par une courte introduction, intitulée " Deux grands traits communs", où l'auteur spécifie les dénominateurs communs des deux littératures : l'utilisation et la maîtrise de la langue française, leur relative jeunesse et leur besoin d'acquérir et d'affirmer leur indépendance de l'ancienne mère-patrie. Ensuite, le chercheur tisse des liens thématiques entre les deux littératures, liens faits de similitudes et d'oppositions. Dans la partie finale, "Mythologies », il ébauche les bases des deux concepts majeurs de sa pensée: l'importance de l'oraliture et l'image de «l'homme américain ». Il y analyse les diverses mythologies américaines, qu'il qualifie de secondaires, car dérivées des mythologies primaires des civilisations-mères. En effet, pour Laroche, l'Amérique est un continent de syncrétisme culturel entre trois grandes cultures : africaine, européenne et amérindienne. $\mathrm{Au}$ croisement de ces trois cultures, l'on retrouve «l'homme américain » : "Un homme venu d'outre-mer et qui a dû rompre avec sa civilisation originelle. Un homme qui a dû recommencer son histoire donc et qui dans ses œuvres d'imagination, ses œuvres littéraires notamment, s'efforce de découvrir le sens de recommencement. » (Le miracle et la métamorphose 231).

De cet individu aux appartenances multiples sont nées plusieurs civilisations, fondées sur des cultures hétérogènes. Le point de départ de l'embranchement réside dans les différentes manières de rompre avec la mère-patrie : du détachement volontaire des Pilgrim Fathers on passe à la déportation forcée des Africains, ou à la condition de semi-abandon des Québécois. Les différentes attitudes se retrouvent dans les mythes de la création propre à chaque civilisation. Laroche souligne l'importance d'étudier et d'analyser non seulement les littératures écrites, mais aussi les littératures orales, par une approche comparatiste et non plus exclusivement ethnologique, afin de déceler les différences et les similitudes des Amériques. Si dans Le Miracle et la Métamorphose surgit le fondement de la pensée larochienne, les autres ouvrages suivront deux parcours divergents mais complémentaires : l'un est consacré au vaste concept d'américanisation, l'autre est focalisé sur la littérature orale haïtienne et ses influences sur l'écrit.

\section{L'oraliture ${ }^{11}$}

L'année 1987 est une date fondamentale dans le parcours de Laroche, car il publie deux ouvrages pionniers consacrés à la relation entre la littérature haïtienne et les autres littératures américaines. Dans les deux textes, Laroche prend en considération des ouvrages

11. Pour plus d'informations voir Virginie Turcotte, Lire l'altérité culturelle dans les textes antillais (2010), où l'auteure reconstruit l'historique du terme, à partir de la première définition d'Ernst Mirville. Voir aussi la définition donnée par Michel Beniamino dans Michel Beniamino et Lise Gauvin, Vocabulaire des études francophones: Les concepts de base (2005). 
haïtiens fortement influencés par la littérature orale et par la culture traditionnelle et populaire du pays. Dans Contribution à l'étude du réalisme merveilleux (1987) il reparcourt le processus de formation et d'évolution du concept de merveilleux dans la littérature et dans la culture haïtiennes pour se concentrer, enfin, sur la pensée de Jacques Stephen Alexis, théoricien du Réalisme merveilleux haïtien. Dans la partie finale l'auteur étend le champ d'analyse en comparant le merveilleux haïtien avec les autres auteurs des merveilleux des Amériques, du Sud au Nord, comme Jorge Amado, Alejo Carpentier ou Toni Morrison, tout en s'appuyant sur les études critiques des spécialistes de chaque pays, comme Françoise Pérus et Selwyn R. Cudjoe.

Le deuxième ouvrage L'avènement de la littérature haïtienne est un recueil d'essais entièrement consacrés à la littérature haïtienne, ou mieux aux littératures haïtiennes : la littérature haïtienne hors d'Haïti, en particulier au Québec ; la littérature haïtienne en Haïti, écrite en français ; et, enfin, la littérature haïtienne en Haïti, écrite en haïtien. Le double mouvement, panoramique et de zoom caractérisant l'attitude critique de Laroche, se retrouve aussi dans cet ouvrage. À la canalisation de l'intérêt pour la construction du modèle haïtien à travers l'évocation du passé africain, la reprise de l'art oral et son influence sur l'écriture, s'ajoute la prise de conscience de l'existence d'une littérature haïtienne en dehors du pays, en diaspora, et de l'exigence d'en analyser les caractéristiques. Il s'agit du premier stade de l'étude de Laroche, où c'est encore la grande littérature qui prime, vu que les analyses conduites détectent les traces des genres oraux dans les ouvrages littéraires haïtiens. Par ailleurs, à cette époque Laroche est déjà conscient de l'importance de la diaspora non seulement au niveau sociopolitique, mais aussi culturel.

La double scène de la représentation (1991), un autre recueil d'essais autour de la littérature haïtienne, reprend les idées élaborées dans L'avènement de la littérature haïtienne et les approfondit. En effet, déjà à partir de l'introduction, on retrouve les deux concepts clés de l'étude conduite dans cet ouvrage : " l'oraliture » et « la double scène de la représentation ». D'abord, Laroche donne un historique du concept d'oraliture, terme forgé en 1970 par Ernst Mirville pour remplacer l'expression « littérature orale »; ensuite, il explique les motivations qui l'ont poussé à récupérer le néologisme de Mirville :

J'ai utilisé ce concept d'oraliture pour analyser des œuvres aussi bien populaires que savantes, orales et écrites. Je le crois effectivement plus opératoire que celui de littérature orale [...]. Je demeure persuadé qu'oraliture traduit fort bien un parallélisme de la littérature et de ce qu'on appelait « littérature orale ». Mais cette dernière expression, manifestement, rendait fort mal la réalité que le terme anglais « oral literature », en préposant le terme « oral» à celui de littérature, indiquait sans doute un peu mieux, au moins pour nos oreilles de Francophones. Si oratura me semble bien fixer l'attention sur la voix (os, oris) oraliture, par la terminaison, attire davantage cette attention sur l'analogie avec la littérature, donc avec l'écriture. (La double scène de la représentation 15-16)

Le lien avec l'écriture, ou pour mieux dire avec la composante esthétique et artistique, est au centre de la réflexion, d'autant plus que Laroche fait tout de suite une distinction entre les oralitures « savante » et « populaire ». La première a ses origines dans l'art de la parole, dans la technique du griot africain ou du samba amérindien, du «marqueur de Parole $»^{12}$ selon la définition des auteurs de la Créolité ; la deuxième est la création anonyme, collective et spontanée de la joute oratoire d'une communauté qui se réunit lors d'une veillée. Toutefois, les deux sont dignes de faire partie de la littérature, car il s'agit

12. Patrick Chamoiseau et Raphaël Confiant, Lettres créoles : Tracées antillaises et continentales de la littérature 1635-1975 (190). 
d'artefacts culturels, détenteurs d'une esthétique puissante. Laroche souligne surtout, en reprenant les discours de Jean Price-Mars et Jacques Stephen Alexis, que le recours à la culture orale et à ses genres de la part des écrivains est un moyen de se protéger et de s'opposer à toute forme de néo-colonisation, comme l'Occupation Américaine (19151934) ou la dictature. De même, le retour aux genres oraux, comme le conte, la lodyans ou tout simplement le teledjòl (racontars) renforce le processus de réappropriation identitaire tant en Haïti que dans ses communautés diasporiques.

Dans un second moment, Laroche se penche sur « l'existence d'une double scène de la représentation littéraire » (19), qui est due non seulement au facteur diasporique, mais aussi à la condition de diglossie de l'écrivain haïtien, le situant entre le créole et le français. Cette situation comporte une triple orientation de la démarche critique : l'analyse des ouvrages de l'oraliture (contes, chansons, lodyans, etc.) par une approche littéraire qui dépasse la méthode ethnologique ; l'observation des rapports entre l'oraliture et la littérature écrite et les influences réciproques; l'étude des deux scènes littéraires haïtiennes, celle "du dedans » et celle "du dehors », en considérant les effets de la diaspora et l'existence de plusieurs types de public (le public haïtien du dedans, le public haïtien du dehors et le public non-haïtien). Or, il ne faut pas oublier que toutes ces approches ont pour but ultime de cerner les différentes facettes de la situation littéraire haïtienne consécutive à sa position diasporique, dispersée et donc plurielle. Il ne s'agit pas seulement de comprendre l'avenir de la littérature haïtienne, mais aussi l'importance de l'oraliture dans la définition de l'identité haïtienne. Le processus est très semblable à celui qui s'est produit sur la scène littéraire québécoise à la suite de la Révolution tranquille. Comme l'affirme Micheline Cambron :

Or, durant cette période [1967-1976], toute production culturelle est évaluée à l'aune de sa québécitude, en termes voilés de correspondance avec un public qui ne se conçoit pas comme virtuel, [...] mais comme une figure réelle de " nous » englobant et occulte qui représente la collectivité. Rien d'étonnant alors à ce que les genres dominants de la période soient aussi ceux qui favorisent le mieux l'illusion du spectateur d'être choisi : les œuvres de l'oralité. (102)

En effet au Québec, depuis toujours, le conte est un des moyens principaux pour la protection et la revalorisation de l'identité culturelle; de plus, dans une époque de renouvellement culturel et social il s'élève à vecteur de socialisation et de partage d'esprit. Ne serait-il donc pas possible que les luttes québécoises pour la récupération du butin identitaire lors de la Révolution Tranquille de même que l'intérêt renouvelé porté à l'oraliture québécoise aient influencé les théories de Laroche sur les trais spécifiques de la littérature haïtienne ? C'est assez probable, car déjà en 1970 il était bien conscient de l'importance de l'oraliture québécoise dans le processus de construction identitaire, comme le confirme son analyse comparative du conte du Petit Chaperon rouge dans la version française, celle de Charles Perrault, et québécoise, celle de Jacques Ferron : « Mais cette appropriation [celle de Ferron] se découvre surtout dans ce que je dénommerais une nationalisation de signification du conte, c'est-à-dire, au fond, l'adaptation de sa portée symbolique aux conditions de la situation du québécois. » (Le miracle et la métamorphose 227). Le rôle central de l'œuvre de Ferron pour la culture québécoise est comparable à l'importance de Jean Price-Mars et, successivement, de Jacques Stephen Alexis pour la culture haïtienne. Dans l'œuvre de Ferron Laroche remarque la réalisation des théories d'Alexis pour un merveilleux engagé, fruit de la culture orale et populaire, qui traite des problématiques socio-économiques du pays et capables de s'adapter aux changements sociaux. Si dans son pays natal le renouveau de l'oraliture s'interrompt avec l'assassinat d'Alexis en 1961, au Québec son succès s'accroît de plus en plus jusqu'à déboucher sur le 
renouveau du conte dans les années 1990. L'élan québécois inspire à Laroche la reprise du projet d'Alexis, mais il va plus loin soit dans la méthode (considérer l'oraliture comme de la littérature) que dans l'élargissement de la mise en perspective, qui devient continental et, ensuite, mondial.

\section{L'homme américain}

L'exotopie est toujours à double sens, car si l'appartenance à la culture québécoise de Laroche a influencé ses recherches sur l'oraliture, son côté haïtien influencera considérablement ses théories sur l'américanisation et la nécessité d'une comparaison interaméricaine. En effet, dans les années 1960 et 1970, l'école comparatiste canadienne se focalisait encore sur les rapports internes entre les littératures francophone et anglophone, ou sur le parallèle avec la littérature étasunienne. Si avec ses premiers ouvrages Laroche élargit sa perspective en y incluant les Caraïbes, avec la parution de Dialectique de l'américanisation (1993), son regard devient continental :

Et pour commencer, [il faudrait] parler un peu plus de l'Amérique ou plus exactement des Amériques. C'est par un coup de force linguistique, du genre des occupations militaires de certains pays par les U.S. Marines, que les citoyens des États-Unis se sont approprié du nom d'Américains. Ils ne sont ni plus ni moins que des États-uniens comme les Mexicains, les Haïtiens, les Canadiens, lesquels sont tous, et chacun à part entière, Américains puisque habitants du continent américain. (69)

Non sans lancer des pointes sur les relations tumultueuses entre Haïti et les ÉtatsUnis, Laroche postule l'abandon d'une vision euro-nord-centrique de la littérature, héritière du colonialisme européen, en faveur de la vision transculturelle propre à l'homme américain, en tant qu'habitant du nord au sud du continent. Ce dernier se réinventera en prenant comme modèles le Caboclo ou le Viens-viens, deux figures légendaires représentant le métissage entre l'Africain et l'Amérindien au Brésil et en Haïti. Dans l'imaginaire populaire des deux pays, il s'agit des indiens rescapés au génocide, réfugiés sur les montagnes, qui se sont ensuite unis aux premiers esclaves africains marrons, auxquels ils ont transmis toutes les connaissances pratiques pour survivre dans le Nouveau Monde. Selon la vision larochienne ces deux personnages mythiques substituent le cowboy étatsunien, incarnation de l'hégémonie symbolique :

Un tel personnage [Caboclo ou Viens-viens] réunirait les qualités non contraires d'être ni Blanc ni Noir ni Rouge mais aussi celles non contradictoires d'être ni non blanc ni non noir ni non rouge. Autrement dit, ni dominant ni dominé mais ni victime ni oppresseur non plus. L'homme d'un monde nouveau, l'Américain à venir : un homme autre, synthèse des hommes présents et non pas leur simple addition. (14)

L'apport amérindien est ainsi au centre de la pensée de Laroche, car il le considère comme fondamental pour la formation culturelle et identitaire de l'homme américain ; en effet, pour l'auteur, tout habitant du continent doit reconnaître la présence et l'apport de la culture amérindienne, aussi importante que l'africaine et l'européenne. Laroche choisit justement le Caboclo ou le Viens-viens, c'est-à-dire des êtres hybrides, fruits de la rencontre entre l'autochtone et le nouvel arrivé, des êtres qui font du partage des connaissances leur objectif primaire. Quelle sera donc la nouvelle littérature du nouvel homme américain? Ou pour mieux dire, quelles seront les nouvelles littératures américaines ? Des littératures en métamorphose permanente, chacune avec sa mythologie, mais consciente de l'existence des autres, toujours en mouvement sans toutefois oublier son passé ; ou, comme le dira Joël Des Rosiers en définissant le concept de métaspora, une 
alliance « de patries, de races, de tribus, de peuples et de langues » (60) qui résistent à l'uniformisation.

Le regard continental devient aussitôt mondial, car déjà à partir de Sémiologie des apparences (1994) les comparaisons ont pour objet non seulement l'Amérique du Sud (en particulier le Brésil) et l'Europe, mais aussi l'Asie, tout en ayant la poésie pour fil conducteur. Un exemple est l'essai sur le poète québécois Gatien Lapointe, où Laroche analyse la démarche poétique de Lapointe à travers une perspective sinologique. Toujours en suivant l'alternance propagation-focalisation, à l'expansion des perspectives analytiques fait suite, dans le même ouvrage, une convergence d'abord sur le folklore haïtien et sur son bestiaire, et après sur le vers créole. Dans un premier temps l'analyse se concentre sur la présence et l'influence du folklore dans la littérature écrite haïtienne et antillaise ; ensuite, Laroche se penche plus profondément sur l'haïtien (en tant que langue) et sur la production en vers créole, en poésie et en musique. Il s'agit, enfin, toujours de l'image du double mouvement de zoom in et zoom out ou de l'action de "voir double», comme le définit Laroche dans l'essai introductif au recueil :

C'est de cela qu'il s'agit finalement. Considérer simultanément l'objet et le sujet, l'autre et moi, mon avoir possible et mon être réel. Faire de même avec les mots, avec la parole des autres comme avec mon propre discours. Car sitôt sorti de moi, le mot me rend autre. Il est mon autre moi. Le je devient autre. Faire la même chose avec la parole des autres mais en sens inverse en veillant à ce que cet autre ne devienne moi trop vite. (15)

Comparer, mais tout en conservant l'intégrité, être en position d'exotopie, regarder de l'extérieur sans se laisser incorporer, sans devenir autre, sans oublier les volontés primaires, c'est-à-dire réévaluer l'oraliture, savante et populaire et ramener la littérature et la culture haïtienne au niveau des autres littératures mondiales, mais toujours en établissant des contacts et des po(i)nts de convergence.

L'ouvrage Littérature haïtienne comparée (2007) est la continuation logique du parcours. La quatrième de couverture affirme tout de suite l'intention de Laroche: «Considérées isolément, les œuvres littéraires haïtiennes paraissent singulières. Elles le sont moins quand on les compare à des œuvres d'autres littératures. » (quatrième de couverture) Il suffit de jeter un coup d'œil à la table des matières pour apercevoir le mouvement en accordéon caractérisant l'approche de Laroche: l'américanisation ${ }^{13}$, l'oraliture ${ }^{14}$, la mondialisation ${ }^{15}$ et la découverte/invention d'Haïti et de ses littératures. Ce dernier point, même si très bref, car épilogue de l'ouvrage, résume toute la pensée de l'essayiste. En effet, en trois pages, on retrouve l'appel soit à la découverte/invention de la littérature haïtienne écrite et orale, en tant que vecteur de la redécouverte identitaire, qu'à l'américanisation, unique réaction possible au processus de colonisation du mot " Amérique ». Un discours qu'implique l'élargissement des perspectives comparatistes à travers un dialogue continu, non seulement en littérature mais plus en général dans la vie quotidienne, car « à trop vouloir s'identifier on finit par ignorer l'identité des autres et par les réduire à l'insignifiance» (234). Le dialogue souhaité implique l'abandon de toute volonté annihilant l'autre et son point de vue, car il faut toujours un interlocuteur parlant et égal, capable de répondre au Je : «Face au Je, il n'y a pas d'interlocuteur, aucun égal

13. «Le circuit du regard latino-américain et caribéen », «Le Brésil, Haïti, l'Amérique » et « Don Juan aux Amériques » traitent de la comparaison interaméricaine.

14. «La figure de Makandal », "Cric? Crac! de Georges Sylvain » et "Bouki et Malis » sont trois textes consacrés aux personnages de la mémoire collective et du folklore haïtiens.

15. Dans « Une crise de possession taoïste » Laroche rapproche le réalisme merveilleux américain du roman chinois Rêve dans le pavillon rouge. 
avec qui dialoguer. Si par hasard il y en avait eu, rendu invisible par la position conquérante de Je, il aurait intérêt à sortir de son anonymat, à affirmer sa présence face à ce Je qui parle en solitaire en prenant la parole » (235).

\section{Conclusion}

Selon Laroche, il faut donc reconquérir la parole enlevée par les colonisations identitaires et culturelles, se réapproprier chaque mot. Cela est l'objectif de son dernier ouvrage édité : Le poids des mots (2013). Dans ce recueil, moins littéraire, plus sociopolitique et subtilement autobiographique, l'auteur pèse chaque mot, il montre le poids authentique des mots, il démontre comment un beignet salé peut enfermer le monde entier. Mots du monde entier et mots d'Haïti, zoom-out et zoom-in, la dialectique larochienne se retrouve encore une fois. D'un côté il lance un appel à « parler non plus seulement de cette mondialisation imposée qui a fait passer l'Afrique en Amérique mais de celle souhaitée, cherchée et pratiquée des échanges entre l'Amérique et l'Afrique et, par là, de l'Afrique et de l'Amérique avec le reste du monde » (49); de l'autre côté, il préconise la construction

[d']un inventaire des mots dont nous nous servons dans nos discours; un inventaire des contes et des récits, des chants et des poèmes dont nous nous servons comme bornes dans notre cheminement intellectuel, émotif et esthétique. Notre littérature, en français ou en haïtien s'inspire de notre oraliture. Mais celleci nous est à nous-mêmes à peine connue, à peine déchiffrée et incomplètement inventoriée. (193)

La société multiculturelle a certainement influencé la démarche critique de Laroche, de cet homme en position d'exotopie, qui aimait se définir Québécois et Haïtien et qui a fait du dialogue entre ses deux patries son but primaire. Et quoi faire si les deux patries en question ont été conquises, dans les deux sens du mot, par les autres? Sans doute instaurer un dialogue multiple, transculturel, un face à face non plus à deux mais à plusieurs, afin de mieux comprendre son propre rôle, comme en témoigne Anthony Phelps : « Le face à face avec des hommes de races et de cultures différentes a amené les écrivains à une meilleure compréhension de leur rôle, c'est-à-dire : porter témoignage de la créativité de leur peuple » (Phelps cité par Mills 113).

Laroche, pour sa part, ne s'est pas limité à " prêcher » le changement, mais il en a aussi donné l'exemple avec son parcours intellectuel, son rôle de passeur culturel, son savoir être " au milieu de », sa capacité de s'adapter aux contextes culturels variés, sans tomber dans le piège de la fusion, mais au contraire, en se laissant enrichir et en même temps en enrichissant les autres dans sa personnelle et éternelle métamorphose d'homme - ou pour mieux dire $n e ̀ g^{16}-\mathrm{d}^{\prime}$ Amérique.

Université de Varsovie

16. En créole haïtien le terme nèg signifie «homme, être humain, homme adulte », voir la définition sur le dictionnaire Diksyonè Krèyol/English/Français sur le site Haïti référence. 


\section{OUVRAGES CITÉS}

Bakhtine, Mikhaïl. Esthétique de la création verbale. Paris, Gallimard, 1984.

Beniamino, Michel et Lise Gauvin. Vocabulaire des études francophones. Les concepts de base. Limoges, Presses universitaires de Limoges, 2005.

Berrouët-Oriol, Robert et Robert Fournier, "L'émergence des écritures migrantes et métisses au Québec »Quebec Studies, 14, 1992, pp. 7-22.

https:/www.researchgate.net/publication/274775454_L'Emergence_Des_Ecritures Migrantes_Et_Metisses_Au_Quebec. Consulté le 14 janvier 2019.

Cambron, Micheline. Une société, un récit. Discours culturel au Québec (19671976). Montréal, Éditions de l'Hexagone, 1989.

Chamoiseau, Patrick et Raphaël Confiant. Lettres créoles. Tracées antillaises et continentales de la littérature 1635-1975. Paris, Hatier, 1991.

Dahouda, Kanaté. " Aimé Césaire, Paul Chamberland et le pays de l'exil » Présence Africaine, 2001/1, n 163-164, pp. 158-167. https://www.cairn.info/revue-presenceafricaine-2001-1-page-158.htm . Consulté le 14 janvier 2019.

---. «Littératures francophones des Antilles et du Québec : Pôles et parallélismes. » Québec français, (127), pp. 30-32, 2002 id.erudit.org/iderudit/55803ac. Consulté le 14 janvier 2019.

Des Rosiers, Joël. Métaspora: essai sur les patries intimes. Montréal, Triptyque, 2013.

Dorsinville, Max. Caliban without Prospero: Essay on Quebec and Black Literature. Erin (Ontario), Press Porcepic, 1974.

---. Le Pays natal: Essais sur les littératures du Tiers-Monde et du Québec. Dakar, Nouvelles Éditions Africaines, 1983.

Jobnel, Pierre. " Maximilien Laroche, critique et spécialiste en littérature comparée. » Le Nouvelliste, 27 juillet 2017 [en ligne], http://lenouvelliste.com/article/46277/maximilien-laroche-critique-et-specialiste-enlitterature-comparee. Consulté le 14 janvier 2019.

Jonaissant, Jean. « De l'apport migratoire à la littérature québécoise » La Licorne, 27, 1993, pp. 391-400.

---. « Des récits haïtiens au Québec (1937-1995). Repères pour une histoire, » Neue Romania, 18, 1997, pp. 81-104.

Kwaterko, Jòzef. «Les fictions identitaires des romanciers haïtiens du Québec » Revue de littérature comparée, 2002/2 (n o 302), pp. 212-229. URL :

https://www.cairn.info/revue-de-litterature-comparee-2002-2-page-212.htm Consulté le 14 janvier 2019.

---. « Pierre Neveu et l'imagination exotopique. » Voix et images, vol. XXXIV, no 1 (100), automne 2008, pp. 67-79.

Icart, Lyonel. «Haïti-en-Québec : Notes pour une histoire. » Ethnologies, vol. 28, no. 1, 2006, pp. 45-79. [en ligne] https://www.erudit.org/fr/revues/ethno/2006-v28-n1ethno1446/014148ar/. Consulté le 14 janvier 2019.

Laroche, Maximilien. Le miracle et la métamorphose. Essai dur les littératures du Québec et d'Haïti. Montréal, Éditions du Jour, 1970.

---. Contribution à l'étude du réalisme merveilleux. Québec, GRELCA, 1987.

---. L'avènement de la littérature haïtienne. Québec, GRELCA, 1987.

---. Juan Bobo, Jan Sòt, Ti Jan et Bad John. Figures littéraires de la Caraïbe. Québec, GRELCA, 1991.

---. La double scène de la représentation. Oraliture et littérature dans la Caraïbe. Québec, GRELCA, 1991.

---. Dialectique de l'américanisation. Québec, GRELCA, 1993.

---. Sémiologie des apparences. Québec, GRELCA, 1994. 
---. Bizango. Essai de mythologie haïtienne. Québec, GRELCA, 1997.

---. Littérature haïtienne comparée. Québec, GRELCA, 2007.

---. Le poids des mots. Québec, GRELCA, 2013.

Mills, Sean. Une place au soleil : Haïti, les Haïtiens et la refondation du Québec. Traduit par Hélène Paré, Montréal, Mémoire d'encrier, 2016.

« Nèg. » Diksyonè kreyòl/english/français, 2007-2018 [en ligne] https://www.haitireference.com/pages/creole/diction/index.php. Consulté le 14 janvier 2019.

Peytard, Jean. Mikhail Bakhtine. Dialogisme et analyse du discours. Paris, BertrandLacoste, 1995.

Phelps, Anthony. «Haïti Littéraire: Rupture et nouvel espace poétique. Exemplaire fraternité. » Île en île,

http://www.lehman.cuny.edu/ile.en.ile/paroles/phelps_haiti-litteraire.html. Consulté le 14 janvier 2019.

---. «Québec-Haïti : Les Chiffonniers de l'exil. » AlterPresse, 29 avril 2013 [en ligne] http://www.alterpresse.org/spip.php?article14468\#.Ws4TG5e-m00. Consulté le 14 janvier 2019.

Selao, Ching. «Les mots/ maux de l'exil/ ex-île. Les romans de Marie-Célie Agnant. » Canadian Literature/Revue canadienne, 204, Spring 2010, pp. 11-25.

---. « Les fils d’Aimé Césaire. De la Martinique au Québec. » Tangence, 98, Winter 2012, pp. 35-56.

---. «Échos de la négritude césairienne chez Gaston Miron et Paul Chamberland. » Voix et Images, 108, Spring-Summer 2011, pp. 99-114.

Todorov, Tzvetan. Mikhaïl Bakhtine : Le principe dialogique. Paris, Seuil, 1981.

Turcotte, Virginie. Lire l'altérité culturelle dans les textes antillais. Montréal, FiguraUqam, 2010.

Vallière, Pierre. Nègres blancs d'Amérique. Montréal, Parti Pris, 1968.

Viatte, Auguste. Histoire littéraire de l'Amérique française. Québec-Paris, Presses Universitaires, 1954. 